\title{
The Influence of Specific Surface Area on the Capacitance of the Carbon Electrodes Supercapacitor
}

\author{
Chih-Ming Wang ${ }^{\mathrm{a},{ }^{*}}$, Chih-Yu Wen ${ }^{\mathrm{b}}$, Ying-Chung Chen ${ }^{\mathrm{b}}$, Jui-Yang Chang ${ }^{\mathrm{b}}$, Chia-Wei Ho ${ }^{\mathrm{b}}$, Kuo-Sheng Kao ${ }^{\mathrm{c}}$, \\ Wei-Che Shih $^{\text {b }}$, Chun-Ming Chiu ${ }^{\text {b }}$, Yu-An Shen ${ }^{\text {b }}$ \\ ${ }^{a}$ Department of Electrical Engineering, Cheng Shiu University, Kaohsiung 833, Taiwan \\ ${ }^{\mathrm{b}}$ Department of Electrical Engineering, National Sun Yat-Sen University, Kaohsiung 804, Taiwan \\ ${ }^{c}$ Department of Computer and Communication, Shu-Te University, Kaohsiung 824, Taiwan
}

*Corresponding Author: cmwang@ @ csu.edu.tw

\begin{abstract}
In this study, the carbon electrode supercapacitors were fabricated using various specific surface areas of active carbon and contents of carbon black. The carbon black was added to increase conductivity of the carbon electrode. To find the optimal processing parameters of the carbon electrode, the effects of various specific surface areas of activated carbon and amounts of carbon black on the capacitive properties of the supercapacitor are investigated. The experimental results showed that the optimum carbon electrode can be obtained using mesocarbon microbeads with a high-specific surface area $\left(2685 \mathrm{~m}^{2} / \mathrm{g}\right)$, a larger pore volume $\left(0.6 \mathrm{~cm}^{3} / \mathrm{g}\right)$, and by adding $10 \mathrm{wt} . \%$ carbon black. The specific capacitance of the carbon electrode in $1 \mathrm{M}$ $\mathrm{KOH}$ is $171.2 \mathrm{~F} / \mathrm{g}$.
\end{abstract}

Keywords: Specific surface area, Activated carbon, Carbon black, Supercapacitor, Specific capacitance.

\section{Introduction}

A supercapacitor is a new energy-storage device positioned between traditional capacitors and batteries, which use electrochemical activated materials or porous materials for storage. Its structure is similar to traditional capacitors and batteries. The advantages of a supercapacitor are high-power density, high-energy density, long-cycle life, and fast-charge/discharge times ${ }^{(1-2)}$. Significant attention has recently focused on electrochemical supercapacitor energystorage systems because of possible applications in electric vehicles and any device that needs a high-pulse discharge profile. Based on the storage mechanism, supercapacitors are divided into two types: electric double-layer capacitors (EDLC) and pseudocapacitors.

It is discovered that charge can be separated by coulomb electrostatic force and form double layers across the surface of the electrode and the electrolyte ${ }^{(3)}$. This concept of an EDLC is applying DC voltage to electrodes that are typically porous carbon, an electric double-layer is established to store charges. A pseudocapacitor stores electrical energy with rapid and continuous redox reactions between the electrode and the electrolyte. Metal oxide and a conducting polymer are commonly used as the electrode materials in pseudocapacitors. Because of the high cost of metal oxide and the poor stability of the conducting polymer, porous carbon is usually chosen as the electrode material for commercialization.

Becker et al. first introduced activated carbon (AC) as the electrode material of EDLC in $1957^{(4)}$. The correlation between the AC porous structure and its electrochemical double-layer capacitance using 50 different activated carbons or carbon fibers has been investigated ${ }^{(5)}$. It is determined that the relationship between specific capacitance and the specific surface of carbon materials is nonlinear because EDLC depends on the electrolyte entering the pores of the AC to store energy. Although the surface area of AC is up to $1000 \sim 2000 \mathrm{~m}^{2} / \mathrm{g}^{(6)}$, it is attributed to the micropores. Because it is difficult for electrolyte ions to enter the micropores, the percentage of the effective surface area of AC used is decreased, and it decreases the specific capacitance. Besides, the AC has a low degree of crystallization and poor conductivity, which is not ideal for charges transfer and causes a loss of energy and power in a device. Thus, it is necessary to add conductive materials into the AC to form a composite electrode and increase its conductivity. The commonly used additive materials include carbon black, metal oxides, conducting polymers, and etc. Although, some researches adopt more effective conducting carbon materials such as carbon nanotubes ${ }^{(7-8)}$, carbon aerogel $^{(9-10)}$, or Graphene ${ }^{(5,11)}$, to enhance a beneficial capacitance, but they are costly and the production techniques are immature.

In this study, the supercapacitors carbon electrodes were fabricated using four kinds of AC with different specific surface areas and the influence of each on capacitance is discussed. Besides, conductive carbon black (CB) is added to improve the conductivity of carbon 
electrodes. The effects of specific surface areas of activated carbon and the content of carbon black on the properties of the supercapacitors are investigated.

\section{Experimental}

\subsection{Preparation of carbon electrodes}

The carbon electrodes used four kinds of $\mathrm{AC}$ and carbon black (CB) as the electrode material. Carbon black was added to improve the electrode conductivity. The $\mathrm{CB}$ content was ranged from 0 to $50 \mathrm{wt} . \%$. After mixing the AC and $\mathrm{CB}$ powders uniformly, they were added to a solution of Polyvinyl butyral (PVB) in Dimethylacetamide (DMA). The PVB content was between 2 and 10 wt. $\%$. The mixture was mixed at room temperature to form carbon slurry. The electrodes were prepared by spin-coating the carbon slurry on the ITO glass and then evaporating the solvent, DMA, in an oven at $150^{\circ} \mathrm{C}$ for $10 \mathrm{~min}$.

In this study, a physical adsorption analyzer was used to explore the BET surface area and the pore structure of AC. The surface morphology of the carbon electrode was analyzed using a field emission scanning microscope (FESEM). Cyclic voltammetry measurements of the carbon electrodes were performed using an electrochemical analyzer (CH Instruments, 611B) in two-electrode cells.

\subsection{The analysis of cyclic voltammetry}

Using cyclic voltammetry (CV), an electrochemical experiment was conducted, not permitting the potential to reverse and allowing the electrode to scan at loop potential. For the CV measurement, two of the same carbon electrodes were used, one side as a working electrode (WE), the other side as a counter electrode (CE) and the reference electrode (RE). The CV curves were adopted to analyze the voltage and current changes, which used $1 \mathrm{M} \mathrm{KOH}$ as an electrolyte and scanned at a scan rate of $25 \mathrm{mV} / \mathrm{s}$ with a voltage range of $-0.5 \mathrm{~V} \sim 0.5 \mathrm{~V}$. The following equation was used to calculate specific capacitance:

$$
C_{S}=\frac{d Q}{d V}=\frac{1}{m v \Delta V} \int_{V_{1}}^{V_{2}} I(V) d V
$$

where $\int_{V_{1}}^{V_{2}} I(V) d V$ is the hysteresis loop area, $v$ is scan rate, $\Delta V$ is the range of potential, $\mathrm{m}$ is the whole weight of the electrode material.

\subsection{The analysis of specific surface area}

The BET theory was used to calculate the specific surface area of materials. In 1938, Stephen Brunauer, Paul Hugh Emmett, and Edward Teller reported a theory to explain the behaviour of vapor molecules adsorbed on a solid surface. The specific surface area, $S_{B E T}$, was given by $^{(12)}$

$$
S_{B E T}=\frac{S_{\text {total }}}{m} \Rightarrow S_{B E T}=\frac{4.35 Q_{m}\left(\mathrm{~cm}^{3} \text { at STP }\right)}{m}
$$

Table1. The four kinds of activated carbon used in this study.

\begin{tabular}{cccc}
\hline No. & $\begin{array}{c}\text { Specific surface area, } \\
\mathrm{S}_{\mathrm{BET}}\left(\mathrm{m}^{2} / \mathrm{g}\right)\end{array}$ & $\begin{array}{c}\text { Pore volume } \\
\left(\mathrm{cm}^{3} / \mathrm{g}\right)\end{array}$ & $\begin{array}{c}\text { Pore size } \\
(\mathrm{nm})\end{array}$ \\
\hline A & 621 & 0.29 & 4.9 \\
B & 997 & 0.57 & 5.4 \\
C & 1982 & 0.38 & 2.7 \\
D & 2685 & 0.60 & 2.5 \\
\hline
\end{tabular}

where $\mathrm{S}_{\text {total }}$ is the total surface area, $Q_{m}$ is the unit of the molar volume of the adsorbate gas .

\section{Results and discussion}

Table 1 presents a summary of the porous structure information of the four kinds of activated carbon used in this study (specific surface area, pore volume, and pore size), in which, sample D shows the largest specific surface area $\left(2685 \mathrm{~m}^{2} / \mathrm{g}\right)$ and the largest pore volume $\left(0.60 \mathrm{~cm}^{3} / \mathrm{g}\right)$. Figure 1 shows the surface SEM micrographs of the AC powders at a magnification of $30,000 \mathrm{X}$. The AC powder with the highest surface area has numerous small particles and pores on its surface. The result is confirmed by the measurement with a physical adsorption analyzer.

Based on the materials parameters of carbon electrodes, AC powders with different surface areas were used for the carbon electrodes. From the literature ${ }^{(13)}$, it showed that adding a small amount of conductive $\mathrm{CB}$ can promote the specific capacitance. In this experiment, $10 \mathrm{wt} \% \mathrm{CB}$ was added to the carbon slurry to increase the conductivity of electrode. The effects of $\mathrm{CB}$ content on the properties of capacitance will be discussed in detail later.

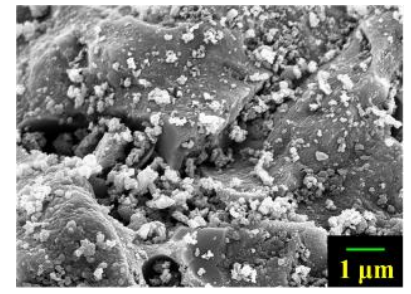

(a)

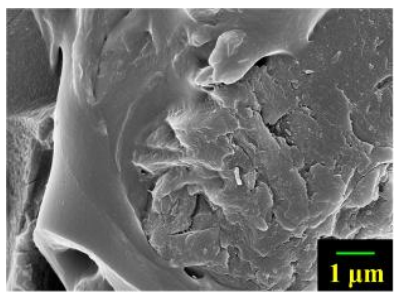

(c)

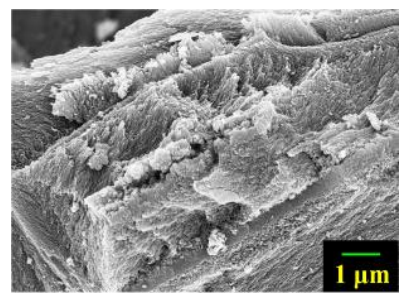

(b)

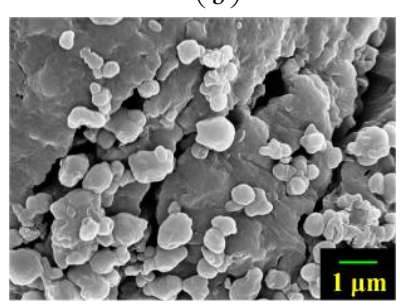

(d)
Fig. 1. SEM morphology of activated carbon with different BET surface area : (a) $621 \mathrm{~m}^{2} / \mathrm{g}$, (b) 997 $\mathrm{m}^{2} / \mathrm{g}$, (c) $1982 \mathrm{~m}^{2} / \mathrm{g}$, (d) $2685 \mathrm{~m}^{2} / \mathrm{g}$. 


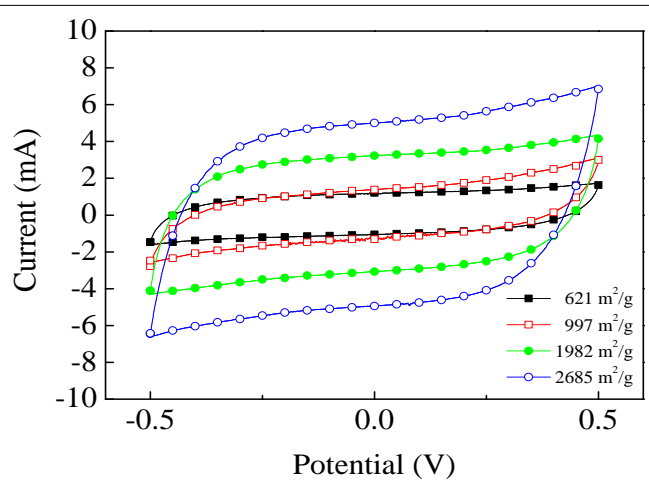

Fig. 2. Cyclic voltammograms of carbon electrodes using activated carbon with different surface area.

After fabrication of carbon electrodes, the capacitive characteristics are analyzed using $\mathrm{CV}$ measurement in $1 \mathrm{M}$ $\mathrm{KOH}$ with a voltage range of $-0.5 \mathrm{~V} \sim 0.5 \mathrm{~V}$ and a scan rate of $25 \mathrm{mV} / \mathrm{s}$. Figure 2 shows that the $\mathrm{CV}$ graphics are approximately rectangle, indicating the carbon electrodes operates charges-storing following the theorem of electric double-layer. As the BET surface area increases, the hysteresis loop area increases and its specific capacitance, calculated using Eq. (1), is raised from $17.68 \mathrm{~F} / \mathrm{g}$ to 171.2 $\mathrm{F} / \mathrm{g}$.

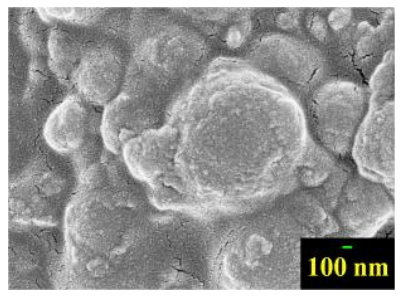

(a)

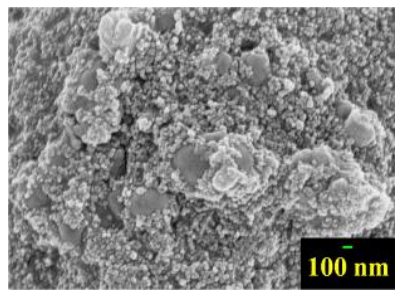

(c)

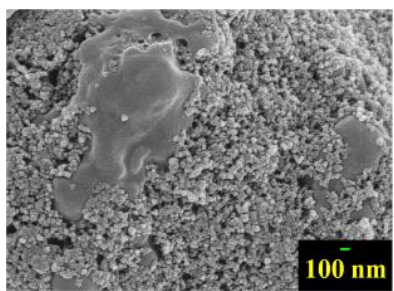

(e)

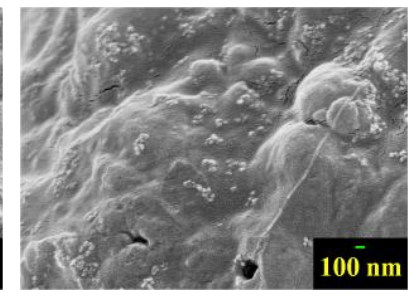

(b)

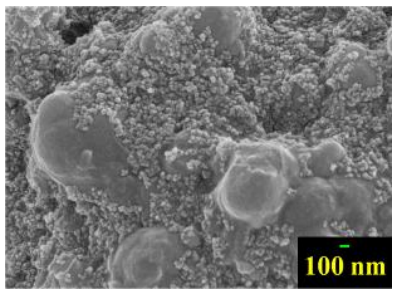

(d)

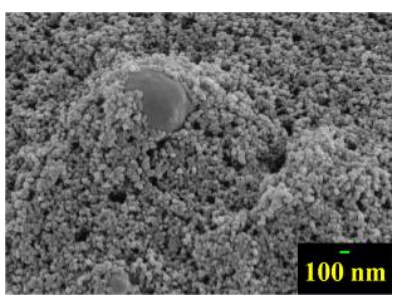

(f)
Fig. 3. SEM morphology of carbon electrode with different amount of carbon black : (a ) $0 \mathrm{wt} . \%$, ( b ) $10 \mathrm{wt} \%$, (c) $20 \mathrm{wt} . \%$, (d) $30 \mathrm{wt} . \%$, (e ) $40 \mathrm{wt} . \%$, (f) $50 \mathrm{wt} . \%$.

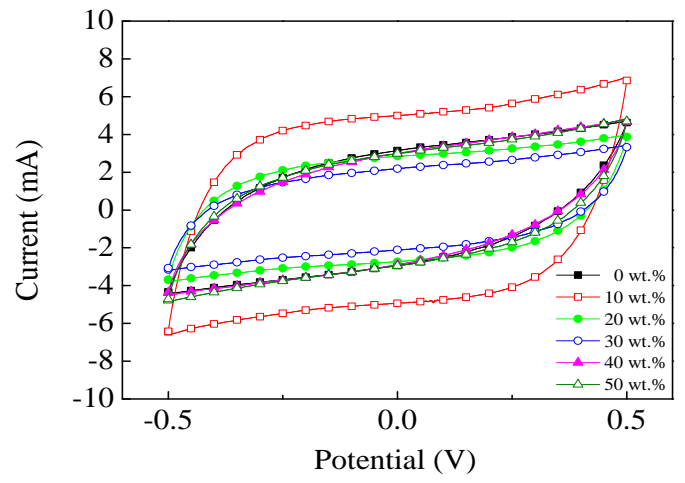

Fig. 4. Cyclic voltammograms of carbon electrodes with different content of carbon black.

Adding conductive $\mathrm{CB}$ in the carbon electrode can promote the capacitive characteristics and increase the conductivity of AC. The influence of $\mathrm{CB}$ content on the characteristics of carbon electrode was investigated by adding CB content from 0 wt.\% to 50 wt.\%. Figure 3 presents the SEM micrographs of the carbon electrode surfaces, showing the surface of AC is covered with tiny $\mathrm{CB}$ powder approximately $16 \mathrm{~nm}$ in size. Figure 3 also shows when the $\mathrm{CB}$ content is greater than $20 \mathrm{wt} \%$, the surface and pores of $\mathrm{AC}$ are almost covered with $\mathrm{CB}$, which exists a smaller BET surface area, and decreases the specific surface area.

Figure 4 shows the CV graphics of carbon electrodes with different content of carbon black. The hysteresis area obviously increased when CB content was less than 10 wt.\%, however, it reduced gradually when the content was greater than 20 wt.\%. According to Eq. (1), the specific capacitance, $\mathrm{C}_{\mathrm{S}}$, is $46.52 \mathrm{~F} / \mathrm{g}$ without adding $\mathrm{CB}$, and $171.2 \mathrm{~F} / \mathrm{g}$ with adding 10 wt. $\%$ of $\mathrm{CB}$. However, when the $\mathrm{CB}$ content increases from $20 \mathrm{wt} . \%$ to $50 \mathrm{wt} . \%$, the $\mathrm{C}_{\mathrm{S}}$ drops from 91.84 $\mathrm{F} / \mathrm{g}$ to $36.76 \mathrm{~F} / \mathrm{g}$.

\section{Conclusions}

This study focuses on the AC electrodes, particularly, the specific surface area and addition of conducting carbon black, to obtain the optimum compositions of composite carbon electrode. In summary, the following two results have been obtained.

(1) When the specific surface area of activated carbon increases from $621 \mathrm{~m}^{2} / \mathrm{g}$ to $2685 \mathrm{~m}^{2} / \mathrm{g}$, the specific capacitance increases from $17.68 \mathrm{~F} / \mathrm{g}$ to $171.2 \mathrm{~F} / \mathrm{g}$. The increment is nonlinear because the specific capacitance is either connected to the specific surface area of the activated carbon or to the pore size and the ion size of electrolyte. Therefore, the activated carbon powder with specific surface area of $2685 \mathrm{~m}^{2} / \mathrm{g}$ and larger pore volume has better capacitance.

(2) When 10 wt.\% carbon black is added to the carbon electrode, the optimized specific capacitance of $171.2 \mathrm{~F} / \mathrm{g}$ can be obtained. However, when the amount of carbon black is increased further, the specific capacitance decreases to $9.19 \mathrm{~F} / \mathrm{g}$. The reason will be attributed to the overlying of carbon black on the activated carbon surface, which will 
decrease the specific surface area and capacitance characteristics. In conclusion, adding of $10 \mathrm{wt} . \%$ conducting carbon black to the carbon electrode will improve electrode conductivity and result in enhanced capacitance.

\section{Acknowledgment}

This study was supported by the Ministry of Science and Technology of the Republic of China, Taiwan, under contract number MOST 103-2221-E-230-018-.

\section{References}

(1) M. Inagaki, H. Konno, and O. Tanaike : "Carbon materials for electrochemical capacitors", Journal of Power Sources, Vol. 195, No. 24, pp. 7880-7903, 2010

(2) D. H. Fritts : "An Analysis of Electrochemical Capacitors", Journal of the Electrochemical Society, Vol. 144, No. 6, pp. 2233-2241, 1997

(3) C. H. Hamann, A. Hamnett and W. Vielstich : "Electrochemistry", Wiley-Vch, Germany, 1998

(4) H. L. Becker, : "Low voltage electrolytic capacitor", US Patent, 2800616, 1957

(5) H. Shi : "Activated carbons and double layer capacitance", Electrochimica Acta, Vol. 41, No. 10, 1633-1639, 1996

(6) P. Simon, and Y. Gogotsi : "Materials for electrochemical capacitors", Nature Materials, Vol. 7, 845-854, 2008

(7) L. Hu, M. Pasta, F. L. Mantia, L. Cui, S. Jeong, H. D. Deshazer, J. W. Choi, S. M. Han and Y. Cui : "Stretchable, Porous, and Conductive Energy Textiles", Nano Letters, Vol. 10, No. 2, 708-714, 2010

(8) R. Salinger, U. Fischer, C. Herta and J. Fricke : "High surface area carbon aerogels for supercapacitors", Journal of Non-Crystalline Solids, Vol. 225, 81-85, 1998

(9) B. Fang, Y. Z. Wei, K. Maruyama and M. Kumagai : "High capacity supercapacitors based on modified activated carbon aerogel", Journal of applied electrochemistry, Vol. 35, No. 3, 229-233, 2005

(10) Y. Wang, Z. Shi, Y. Huang, Y. Ma, C. Wang, M. Chen and Y. Chen : "Supercapacitor Devices Based on Graphene Materials", Journal of Physical Chemistry C, Vol. 113, No. 30, 13103-13107, 2009

(11)X. Du, P. Guo, H. Song and X. Chen : "Graphene nanosheets as electrode material for electric doublelayer capacitors", Electrochimica Acta, Vol. 55, No. 16, 4812-4819, 2010

(12) S. Brunauer, P. H. Emmett, and E. Teller : "Adsorption of Gases in Multimolecular Layers", Journal of the American Chemical Society, Vol. 60, No. 2, 309-319, 1938

(13) N. L. Wu and S. Y. Wang : "Conductivity percolation in carbon-carbon supercapacitor electrodes", Journal of Power Sources, Vol. 110, No. 1, 233-236, 2002 